[Agr. Biol. Chem., Vol. 33, No. 10, p. 1387 1398, 1969]

\title{
Studies on Amino Acid Contents of Processed Soybean
}

\section{Part XI. Evaluation of Nutritional Losses of Overheated Defatted Soybean Flour}

\author{
By Harue Taira, Tatsuo Koyanagi, ${ }^{*}$ Teru Takanohashi ${ }^{* *}$ \\ and Keiko OrKawa ${ }^{* *}$ \\ Food Research Institute, Ministry of Agriculture and Forestry, Shiohama, \\ Kotoku, Tokyo \\ * Laboratory of Nutrition, Faculty of Agriculture, Tohoku University, Sendai \\ * Department of Home Economics, Iwate University, Morioka
}

Received December 6, 1968

Effect of heating on the nutritive value of defatted soybean four has been investigated by animal experiments. Loss due to heat degradation was evaluated in two ways. In the first method, the amino acids lost during overheating were supplemented by cystine and mixture of lysine, arginine, tryptophan, and serine at dietary levels of $1.6 \%$ nitrogen, and cystine and mixture of those amino acids plus histidine at dietary levels of $3.20 \%$ nitrogen. The other procedure adopted was the absorbent test used with amino acid mixtures based on the pattern of amino acids released by pancreatic hydrolysis of unheated, properly heated, and overheated defatted soybean flour at 6 and $120 \mathrm{hr}$ hydrolysis.

At $1.6 \%$ dietary nitrogen level, the nutritive value of overheated soybean flour increased by supplementation with cystine and amino acid mixture, but at the $3.2 \%$ nitrogen level only cystine was effective. Supplementation of lost amino acids to overheated flour did not restore the nutritive value to that of the properly heated flour. Based on the amino acids released by pancreatic hydrolysis of unheated, properly heated, and overheated soybean flour after 6 and $120 \mathrm{hr}$ reaction, amino acid mixtures were prepared and tested for their nutritive value. While the nutritive value of amino acid mixture prepared based on the pattern of amino acid liberated by $6 \mathrm{hr}$ digestion of unheated, properly heated, and overheated flour did not show similar trend to that of 3 kinds of flour itself, the nutritive value of the amino acid mixture prepared after the data obtained by 120 hr digestion agreed well with the trend of unheated or heated soybean flour.

The nutritive value was also measured by the nitrogen balance of test animals.

Osborne and Mendel ${ }^{11}$ have reported that nutritive value of soybeans improved by mild heating. Improvement in the nutritive quality is partly due to the destruction of trypsin inhibitor(s) $)^{2-41}$ and also to the denaturation

1) T.B. Osborne and L. B. Mendel, J. Biol. Chem., 32, 369 (1917).

2) M. Kunitz, Science, 101, 668 (1945).

3) D. Melnick, B. L. Oser and S. Weiss, ibid., $103,326(1946)$.

4) R. J. Westfall and S. M. Hauge, J. Nutr., 35 $379(1948)$ of protein by increasing the digestibility and making sulphur containing amino acids available. $^{3,51}$ Overheating of soybean flour, on the other hand, not only destroys amino acids $^{6,71}$ but also decreases the biological

5) K. Guggenheim, S. Halevy and N. Friedmann, Arch. Biochem. Biophys., 91, 6 (1960).

6) H. Taira, H. Taira, K. Sugimura and $Y$. Sakurai, Agr. Biol. Chem., 29, 1074 (1965).

7) H. Taira, H. Taira, K. Sugimura and Y. Sakurai, ibid., 29, 1080 (1965). 
value. ${ }^{8-121}$ The loss in nutritive value of soybean flour can be restored by supplementation of diets with lysine and methionine, ${ }^{9 \sim 11}$ or lysine, methionine and cystine. ${ }^{12)}$ Iriarte and Barnes ${ }^{131}$ observed that addition of cystine to overheated soybean products improved the nutritive value, but not to its optimum level. It is well known that nutritive value of protein depends not only the pattern of its amino acid composition but also its physiological availability.

Of the several characteristics which determine the nutritional quality of processed protein foods, their digestibility is of paramount importance. For evaluating the nutritional value, the most common procedure is in vitro tests. It has been reported that correlation exists between the nutritive value and the index of enzymatic hydrolysis. ${ }^{14-19 !}$ Nutritive evaluation of heat processed protein foods by enzymatic digestion procedure is necessary because the amino acids present in the protein may only be partially available or completely unavailable.

The present studies were undertaken to determine the effect of heating on the nutritive value of defatted soybean flour. The experiment was designed with the twin objective of finding out the nutritive value of

8) Y. Hayashi and H. Ariyama, Eiyo to Shokuryo, 13, 297 (1961).

9) D.R. Clandinin, W.W. Cravens, C.A. Elvehjem and J. C. Halpin, Poultry Sci., 25, 399 (1946).

10) D.R. Clandinin, W.W. Cravens, C.A. Elvehjem and J. G. Halpin, ibid., 26, 150 (1947).

11) J.C. Fritz, E. H. Kramke and C. A. Reed, ibid., 26, 657 (1947).

12) J, McGinnis and R.J. Evans, J. Nutr., 34, 725 (1947)

13) B. J. R. Iriarte and R. H. Barnes, Food Technol., 20, $835(1966)$.

14) D. Melnick and B. L. Oser, ibid., 3, 57 (1949).

15) J. F. Beuk, F. W. Chornock and E. E. Rice, J. Biol. Chem., 180, 1243 (1949).

16) M.J. Horn, A. E. Blum and M. Womack, J. Nutr., 52, 375 (1954).

17) R. J. Evans, J. McGinnis and J. L. St. John, ibid., 33, 661 (1947).

18 G. R. Ingram, W. W. Cravens and C.A. Elvehjem, Poultry Sci., 29, 590 (1950).

19) W. R. Akeson and M. A. Stahmann, J. Nutr., 83, 257 (1964). overheated soybean flour after supplementing the amino acids lost during heating, and of amino acid mixtures based on the amino acids released by enzymatic digestion.

\section{EXPERIMENTAL}

Preparation of diets

A. Heat treatment of soybean flour and amino acid supplementation

a. Heat treatment of soybean flour. Defatted soybean flakes were obtained from Ajinomoto Co. Inc. It was prepared by extracting the oil from the raw soybean flakes with $n$-hexane by Lurgi-type extractor. The flakes were ground to pass through a 40 -mesh standard screen.

Heat treatment was carried out by autoclaving the defatted soybean flour at $0.35 \mathrm{~kg} / \mathrm{cm}^{2}\left(108^{\circ} \mathrm{C}\right)$ for $1 \mathrm{hr}$ (properly heated) ${ }^{6}$ and at $1.4 \mathrm{~kg} / \mathrm{cm}^{2}\left(126^{\circ} \mathrm{C}\right)$ for $4 \mathrm{hr}$

Table I. Destruction of Amino Acids in Defatted SOYbean Flour Subjected TO DIFFERENT HEAT TREATMENTS $(\mathrm{g} / 16 \mathrm{gN})$

Heat treatment Un UnTemp. $\left({ }^{\circ} \mathrm{C}\right)$
Time $(\mathrm{hr})-$ Properly Overheated

Amino acids Glycines 4.3 heated
$\left(108^{\circ} \mathrm{C}\right)$ 1 $\left(126^{\circ} \mathrm{C}\right)$ 4

Alanine

Valine

(a)

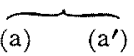

$4.2 \quad 4.3$

(b) $\left(\mathrm{b}^{\prime}\right)$

Isoleucine

4.5

4.5

4.5

$4.4 \quad 4.3$

Leucine

5.4

5.4

5.3

$4.4 \quad 4.3$

Aspartic a

4.8

4.8

4.8

$5.4 \quad 5.3$

rtic acid

8.3

8.2

8.3

$4.9 \quad 4.8$

Glutamic acid

Lysine

20.8

11.9

11.9

$8.6 \quad 8.4$

Arginine

7.0

20.8

Histidine

6.5

7.0

$20.6 \quad 21.1 \quad 21.0$

Phenylalanine

2.5

Tyrosine

7.0

$5.2 \quad 5.6$

Proline

$4.7 \quad 4.7$

6.5

$5.2 \quad 5.9$

Tryptophan

3.23 .2

2.5

$2.5 \quad 2.3$

Methionine

$5.4 \quad 5.5$

$4.7 \quad 4.7$

Cystine

1. $40 \quad 1.40$

3.2

5.5

$3.2 \quad 3.2$

$\begin{array}{llll}40 & 1.40 & 1.27 & 1.12\end{array}$

$\begin{array}{llllll}0.95 & 0.97 & 0.95 & 0.94 & 0.95\end{array}$

Serine

$\begin{array}{lllll}1.20 & 1.20 & 1.20 & 0.71 & 0.65\end{array}$

Threonine

Total $\begin{array}{llllll}6.4 & 6.4 & 6.4 & 6.0 & 6.3\end{array}$

$\begin{array}{lllll}4.6 & 4.6 & 4.6 & 4.7 & 4.6\end{array}$

$\begin{array}{llllll}103.85 & 103.77 & 103.65 & 100.52 & 100.72\end{array}$ 
(overheated) ${ }^{6}$ in the presence of an equal weight of water. ${ }^{7}$ Each sample was lyophilized and ground to pass through a 40 -mesh standard screen.

Amino acid composition of the samples was determined by microbiological assay ${ }^{6}$ after acid or alkaline hydrolysis. Amino acid values of unheated, properly heated, and overheated soybean flours are expressed as $\mathrm{g}$ per $16 \mathrm{~g}$ of total nitrogen of each sample and the data are presented in Table I.

b. Amino acid supplementation. Overheating destroyed cystine, lysine, arginine, tryptophan, and serine (sample b), and also histidine in sample $b^{\prime}$ of treated soybean flour. Supplementation test with overheated defatted soybean flour was carried out by the addition of amino acids at levels comparable to those destroyed during overheating. The composition of diets is presented in Table II. Heated soybean flour and supplemented diet with amino acid were tested at dietary nitrogen levels of 1.6 and $3.2 \% .201$

B. The diets containing amino acid mixture in accordance with the released amino acid patterns of pancreatic hydrolysates

a. Digestion with pancreatin. The procedure de- scribed by Melnick4 and Hoshino et al.211 was followed in the preparation of samples. The raw and heated defatted soybean flour containing $6 \mathrm{~g}$ protein was suspended in $50 \sim 60 \mathrm{ml}$ of distilled water and $30 \mathrm{ml}$ of phosphate buffer solution $(750 \mathrm{ml}$ of $\mathrm{M} / 5 \quad \mathrm{KH}_{2} \mathrm{PO}_{4}$ plus $144 \mathrm{ml}$ of $1 \mathrm{M} \mathrm{NaOH}$, diluted to $1000 \mathrm{ml}$ ) of $\mathrm{pH} 8.4$ was added and the volume was made up to $130 \mathrm{ml}$ with distilled water. Then $20 \mathrm{ml}$ of the same buffer containing $200 \mathrm{mg}$ of pancreatin (Hishiyama Seiyaku Co. Inc.) was added, and the reaction mixture was preserved under $10 \mathrm{ml}$ of toluene. The mixture was incubated at $37^{\circ} \mathrm{C}$, and the samples were drawn at intervals of $0,6,18,24,48$, and $120 \mathrm{hr}$ to find out the effect of time on enzyme treatment. Soon after drawing the samples, the digests were heated in a boiling water bath for $10 \mathrm{~min}$, cooled, and filtered. The filtrates were adjusted to $\mathrm{pH} 6.8$, diluted to the analytical range of amino acid concentration and frozen until analyzed.

The hydrolysates were assayed by microbiological method described previously, 22 , The free amino acid value means the free amino acid available to the test strains of lactic acid bacteria. The data are presented in Table III.

Table II. Composition of Diets for Different Groups Prepared from Heat TREATED SOYBEAN FLoUR

\begin{tabular}{|c|c|c|c|c|c|c|c|c|c|}
\hline Components $\quad$ Groups & A & $\mathrm{B}$ & C & $\mathrm{D}$ & $\mathrm{E}$ & $\mathrm{F}$ & $\mathrm{G}$ & $\mathrm{H}$ & I \\
\hline Properly heated soybean flour & $20.4^{11}$ & & & & $44.7^{51}$ & & & & \\
\hline Overheated soybean flour & & $20.3^{21}$ & $20.3^{2}$ & $20.3^{2 i}$ & & $44.3^{61}$ & $44.3^{6}$ & $44.3^{6}$ & \\
\hline Supplemental amino acids & & & $0.428^{31}$ & $0.473^{4}$ & & & 0.747 & $0.85^{8}$ & \\
\hline Salts & 4.0 & 4.0 & 4.0 & 4.0 & 4.0 & 4.0 & 4.0 & 4.0 & 4.0 \\
\hline Water-soluble vitamins ${ }^{9}$ & 1.0 & 1.0 & 1.0 & 1.0 & 1.0 & 1.0 & 1.0 & 1.0 & \\
\hline Fat-soluble vitamins in soybean oi & il 5.0 & 5.0 & 5.0 & 5.0 & 5.0 & 5.0 & 5.0 & 5.0 & \\
\hline Starch (Potato starch) & 69.6 & 69.7 & 69.3 & 69.2 & 45.3 & 45.7 & 45.0 & 44.8 & 90.0 \\
\hline Total & 100 & 100 & 100 & 100 & 100 & 100 & 100 & 100 & 100 \\
\hline Diet $\mathrm{N}$ & 1.60 & 1.60 & 1.68 & 1.69 & 3.20 & 3.20 & 3.37 & 3.38 & 0 \\
\hline
\end{tabular}

1) Sample a in Table I (N: 7.8506 ).

2) Sample b in Table I (N: $7.880 \mathrm{O}$ ).

3) 2) plus $221 \mathrm{mg} \mathrm{L}-\mathrm{Lys} \cdot \mathrm{HCl}, 166 \mathrm{mg} \mathrm{L}-\mathrm{Arg} \cdot \mathrm{HCl}, 10 \mathrm{mg}$ L-Try and $31 \mathrm{mg} \mathrm{L}-\mathrm{Ser}$.

4) 3) plus $45 \mathrm{mg}$ L-Cys.

5) Sample $a^{\prime}$ in Table $I$ (N: $\left.7.10^{\circ}\right)$.

6) Sample $b^{\prime}$ in Table I (N: $7.22 \%$ ).

7) 6) plus $350 \mathrm{mg} \mathrm{L}-\mathrm{Lys} \cdot \mathrm{HCl}, 150 \mathrm{mg} \mathrm{L}-\mathrm{Arg} \cdot \mathrm{HCl}, 83 \mathrm{mg} \mathrm{L}-\mathrm{His} \cdot \mathrm{HCl}, 106 \mathrm{mg}$ DL-Try and $49 \mathrm{mg}$ L-Ser.

8) 7) plus $110 \mathrm{mg}$ L-Cys.

9) A. E. Harper, J. Nutr., 68, 405 (1959).

20) R. H. Barnes, M.J. Bates and J. E. Maack, J. Nutr., 32, 535 (1946).
21) N. Hoshino, S. Tamura, A. Kawabata, A. Taima and H. Hara, Eiyo to Shokuryo, 16, 377 (1964). 22) H. Taira, H. Taira and Y. Sakurai Nippon Nogeikagaku Kaishi, 40, 41 (1966). 
Table III. The Effect of Heating on the Liberation of amino

Heat treatment

Digestion period (hr)

Unheated

\begin{tabular}{|c|c|c|c|c|c|c|c|c|}
\hline \multirow{2}{*}{ (hr) } & \multirow[b]{2}{*}{0} & \multirow[b]{2}{*}{6} & \multirow[b]{2}{*}{18} & \multirow[b]{2}{*}{24} & \multirow[b]{2}{*}{48} & \multirow[b]{2}{*}{120} & \multirow[b]{2}{*}{0} & \multirow[b]{2}{*}{6} \\
\hline & & & & & & & & \\
\hline Glycine & 0.05 & 0.06 & 0.11 & 0.14 & 0.14 & 0.25 & 0.05 & 0.08 \\
\hline Alanine & 0.02 & 0.43 & 0.78 & 0.72 & 0.74 & 0.70 & 0.06 & 0.32 \\
\hline Valine & 0.07 & 0.19 & 0.31 & 0.37 & 0.50 & 0.85 & 0.08 & 0.17 \\
\hline Isoleucine & 0.05 & 0.14 & 0.29 & 0.37 & 0.41 & 0.73 & 0.05 & 0.17 \\
\hline Leucine & 0.06 & 0.18 & 0.30 & 0.39 & 0.66 & 0.92 & 0.10 & 0.32 \\
\hline Aspartic acid & 0.12 & 0.28 & 0.36 & 0.44 & 0.45 & 0.53 & 0.14 & 0.24 \\
\hline Glutamic acid & 0.20 & 0.25 & 0.34 & 0.38 & 0.75 & 0.82 & 0.18 & 0.33 \\
\hline Lysine & 0.09 & 0.12 & 0.30 & 0.46 & 0.56 & 0.76 & 0.15 & 0.32 \\
\hline Arginine & 0.14 & 0.24 & 0.36 & 0.34 & 0.40 & 0.49 & 0.21 & 0.46 \\
\hline Histidine & 0.08 & 0.15 & 0.26 & 0.34 & 0.37 & 0.67 & 0.10 & 0.18 \\
\hline Phenylalanine & 0.10 & 0.21 & 0.29 & 0.40 & 0.82 & 1.14 & 0.12 & 0.39 \\
\hline Tyrosine & 0.07 & 0.56 & 0.71 & 0.74 & 0.81 & 1.18 & 0.08 & 0.49 \\
\hline Proline & 0.06 & 0.08 & 0.13 & 0.18 & 0.31 & 0.37 & 0.06 & 0.10 \\
\hline Tryptophan & 0.03 & 0.31 & 0.44 & 0.48 & 0.39 & 0.44 & 0.06 & 0.22 \\
\hline Methionine & 0.02 & 0.04 & 0.08 & 0.12 & 0.15 & 0.19 & 0.02 & 0.05 \\
\hline Cystine & 0.0010 & 0.0037 & 0.0038 & 0.0048 & 0.0072 & 0.0145 & 0.0011 & 0.0023 \\
\hline Serine & 0.07 & 0.14 & 0.21 & 0.29 & 0.32 & 0.53 & 0.12 & 0.26 \\
\hline Threonine & 0.08 & 0.55 & 1.32 & 1.55 & 1.63 & 2.07 & 0.15 & 0.87 \\
\hline Total & 1.3110 & 3.9337 & 6.5938 & 7.7148 & 9.4172 & 12.6545 & 1.7311 & 4.9723 \\
\hline
\end{tabular}

Table IV. Amino Acid Composition of Different Diets Compounded BY USING AMINO ACID MIXTURES*

Amino acids
Glycine
L-Alanine
L-Valine
L-Isoleucine
L-Leucine
L-Aspartic acid
L-Glutamic acid
L-Lysine**
L-Arginine**
L-Histidine**
L-Phenylalanine
L-Tyrosine
L-Proline
L-Tryptophan
L-Methionine
L-Cystine
L-Serine
L-Threonine
Total

\begin{tabular}{rrr} 
& & \multicolumn{1}{c}{ Amin } \\
${^{\prime}} }$ & $\mathrm{E}^{\prime}$ & $\mathrm{F}^{\prime}$ \\
1.53 & 1.60 & 2.25 \\
10.93 & 6.44 & 2.91 \\
4.83 & 3.42 & 3.58 \\
3.56 & 3.42 & 2.25 \\
4.58 & 6.44 & 8.98 \\
7.11 & 4.83 & 6.07 \\
6.36 & 6.64 & 5.41 \\
3.05 & 6.44 & 7.40 \\
6.10 & 9.25 & 15.72 \\
3.81 & 3.62 & 3.41 \\
5.34 & 7.84 & 9.56 \\
14.24 & 9.85 & 6.32 \\
2.03 & 2.01 & 1.91 \\
7.88 & 4.42 & 3.58 \\
1.02 & 1.01 & 1.08 \\
0.09 & 0.05 & 0.03 \\
3.56 & 5.23 & 5.82 \\
13.98 & 17.50 & 13.72 \\
100 & 100 & 100
\end{tabular}

$$
\text { no acids }
$$

$\mathrm{G}^{\prime}$

\begin{tabular}{lrr}
$\mathrm{G}^{\prime}$ & \multicolumn{1}{c}{$\mathrm{H}^{\prime}$} & \multicolumn{1}{c}{$\mathrm{I}^{\prime}$} \\
1.98 & 3.22 & 3.01 \\
5.53 & 3.71 & 4.03 \\
6.72 & 5.52 & 5.75 \\
5.77 & 4.89 & 4.29 \\
7.27 & 8.93 & 10.37 \\
4.19 & 4.74 & 3.96 \\
6.48 & 4.82 & 6.82 \\
6.01 & 6.97 & 6.34 \\
3.87 & 11.49 & 11.91 \\
5.29 & 4.11 & 3.19 \\
9.01 & 8.23 & 8.39 \\
9.32 & 7.75 & 7.33 \\
2.92 & 3.52 & 3.30 \\
3.48 & 3.56 & 3.04 \\
1.50 & 1.56 & 1.58 \\
0.11 & 0.18 & 0.10 \\
4.19 & 7.08 & 8.10 \\
16.36 & 9.72 & 8.50 \\
100 & 100 & 100
\end{tabular}

(\%)

* Composition was based on the pattern of amino acid released by enzymatic hydrolysis of unheated, properly heated, and overheated soybean flour at 6 and $120 \mathrm{hr}$ digestion.

$D^{\prime}=6 \mathrm{hr}$ digestion of unheated flour; $E^{\prime}=6 \mathrm{hr}$ digestion of properly heated flour; $F^{\prime}=6 \mathrm{hr}$ digestion of overheated flour; $\mathrm{G}^{\prime}=120 \mathrm{hr}$ digestion of unheated flour; $\mathrm{H}^{\prime}=120 \mathrm{hr}$ digestion of properly heated flour; $\mathrm{I}^{\prime}=$ $120 \mathrm{hr}$ digestion of overheated flour.

** Listed here as the free base but added to the diets as the hydrochlorides. 


\begin{tabular}{cccc} 
Properly heated & & \\
\hline 18 & 24 & 48 & 120 \\
0.20 & 0.33 & 0.55 & 0.87 \\
0.58 & 0.96 & 0.98 & 1.00 \\
0.50 & 0.61 & 0.99 & 1.49 \\
0.37 & 0.62 & 0.99 & 1.32 \\
0.83 & 1.06 & 1.58 & 2.41 \\
0.74 & 1.09 & 1.20 & 1.28 \\
0.62 & 0.86 & 1.00 & 1.30 \\
0.81 & 1.05 & 1.66 & 1.88 \\
1.22 & 1.80 & 2.69 & 3.10 \\
0.44 & 0.60 & 0.78 & 1.11 \\
0.82 & 1.17 & 1.48 & 2.22 \\
0.63 & 1.15 & 1.40 & 2.09 \\
0.24 & 0.49 & 0.61 & 0.95 \\
0.40 & 0.60 & 0.74 & 0.96 \\
0.13 & 0.20 & 0.26 & 0.42 \\
0.0053 & 0.0083 & 0.0161 & 0.0476 \\
0.60 & 1.11 & 1.35 & 1.91 \\
1.63 & 1.86 & 2.22 & 2.62 \\
10.7653 & 15.5683 & 20.4961 & 26.9776
\end{tabular}

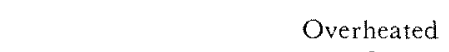

\begin{tabular}{llllll}
\hline 0 & 6 & 18 & 24 & 48 & 120
\end{tabular}

0.10

0.27

0.11

0.35

0.49

0.51

$0.64 \quad 0.82$

0.13

0.43

0.07

0.27

0.58

0.75

$0.76 \quad 1.10$

0.20

1.08

0.88

0.62

0.98

$\begin{array}{ll}1.30 & 1.57\end{array}$

0.25

0.73

2.26

0.67

0.92

2.69

2.35

0.84

0.99

1.10

1.17

0.24

0.65

1.05

0.89

0.16

0.67

1.89

0.97

1.32

1.59

2.83

0.15

0.41

2.31

1.20

1. 36

2.79

3.35

0.69

0.66

1.72

0.81

1.92

1.41

1.91

0.58

0.75

0.47

0.23

0.10

0.43

0.71

0.67

0.81

0.37

0.30

0.0096

0.0151

1.88

1.69

2.12

1.86

24.1051

1.86

1. .73

3.25

0.87

2.29

2.00

0.90

0.83

0.43

0.0265

0.37

1. 65

1.70

20.6796

2.21

2.32

27.2865

TABle V. Composition of Diets USED IN THE ANIMAL EXPERIMENTS

(\%)

Components

Groups $A^{\prime}$

$\mathrm{C}^{\prime} \quad \mathrm{D}$

Unheated soybean flour

(N: $6.65 \%)$

36.10

Properly heated soybean flour (N: $7.19 \%$ )

32.05

Overheated soybean flour

(N: $7.62,0)$

31.50

Amino acid mixture*

$\mathrm{D}^{\prime}(\mathrm{N}: 12.67 \%)$

$E^{\prime}(N: 13.1896)$

$F^{\prime}(\mathrm{N}: 14.2105)$

$\mathrm{G}^{\prime}(\mathrm{N}: 12.1396)$

$\mathrm{H}^{\prime}$ (N: 13.93\%)

$I^{\prime}$ (N: $\left.13.61 \%\right)$

Casein (N: 13.3796)

Salts**

Water-soluble vitamins**

Fat-soluble vitamins in soybean oil

Starch (Potato starch)

Total

Diet $N$

18.96

18.21

16.89

19.80

$$
17.23
$$

$\begin{array}{llllllllll}6.0 & 6.0 & 6.0 & 6.0 & 6.0 & 6.0 & 6.0 & 6.0 & 6.0 & 0\end{array}$

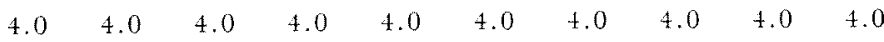

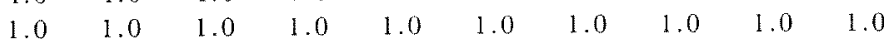

$\begin{array}{llllllllll}5.0 & 5.0 & 5.0 & 5.0 & 5.0 & 5.0 & 5.0 & 5.0 & 5.0 & 5.0\end{array}$

$\begin{array}{llllllllll}47.90 & 51.95 & 52.50 & 65.04 & 65.79 & 67.11 & 64.20 & 66.77 & 66.36 & 90.00\end{array}$

$\begin{array}{llllllllll}100 & 100 & 100 & 100 & 100 & 100 & 100 & 100 & 100 & 100\end{array}$

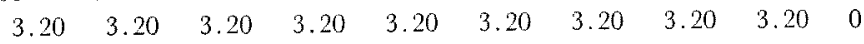

* Sec the Table IV.

** A. E. Harper, J. Nutr., 68, 405 (1959). 
b. Preparation of amino acid mixture. Casein plus soybean flour of different heat treatment or casein plus amino acid mixture was included in diets at the level of $3.2 \%$ nitrogen. In all cases, casein was used at a level of $0.80 \%$ nitrogen. The amino acid mixtures were prepared, based on the pattern of amino acids released during the enzymatic hydrolysis of unheated, properly heated, and overheated soybean flour after 6 and $120 \mathrm{hr}$ of digestion (Table IV). All amino acids used were L-isomers.

\section{Animal experiments \\ Male weanling rats of the Wister strain weighing about $50 \sim 60 \mathrm{~g}$ were used in this study. The rats were maintained on a stock diet for one week, divided into groups of 6 animals each and housed in indi- vidual wire-bottom cages. Only 4 animals were used in the group $\mathrm{A}$ to $\mathrm{D}$ of the experiments (Table II). Food and water were given ad libitum for three weeks and the animals were weighed weekly. I and $\mathrm{J}^{\prime}$ groups of rats were fed a protein-free diet, and the figures for nitrogen retention and biological value have been corrected for metabolic and endogenus losses.}

\section{Absorbability measurement}

Rats belonging to groups E-I (Table II) and $A^{\prime}-J^{\prime}$ (Table V) were fed diets of $3.2 \%$ nitrogen levels for 3 weeks. Food consumption was recorded daily, and feces and urine were collected for 3 days during the last week. Nitrogen quality and nitrogen balance were calculated by determining nitrogen in feed, feces, and urine by the macro-Kjeldahl method.

\section{RESULTS AND DISCUSSION}

Effect of amino acid supplementation to overheated defatted soybean flour

Amino acids lost during heating were supplemented and nitrogen quality and nitrogen balance of overheated flour were determined. Nutritive value of properly heated flour was also found out and the relevant data are presented in Table VI.

a. Nitrogen quality When the dietary nitrogen level was $1.6 \%$, nitrogen efficiency ratio (NER) of properly heated flour (group A) and overheated flour (group B) was 9.54 and 0.83 , respectively. Results of group $\mathrm{C}$ indicates that NER of group B could be increased by the addition of mixture of amino acids lost during heating, i.e. lysine, arginine, tryptophan, and serine, even without cystine. Even though the NER of Group D diet (group C diet plus cystine) increased, it did not reach the level of group A. In the same experiment when the level of nitrogen was increased to $3.2 \%$ in the diets, NERs of properly heated flour (group E) and overheated flour (group F) were 8.74 and 4.85 , respectively. Reduced NER of the overheated flour (diet of group F) did not increase much when supplemented with mixture of lysine, arginine, histidine, tryptophan, and serine (group G). In the group $H$ (group $G$ diet plus cystine), the NER increased, but did not reach that of properly heated flour. From these results on rat growth, it is obvious that supplemental addition of cystine and amino acid mixture lost during heating were found to be effective at $1.6 \%$ nitrogen levels, but those amino acids mixture plus histidine, except cystine, had no beneficial effect at levels of $3.2 \%$ nitrogen in the diet.

It has been recognized that excessive heating damages the nutritive value of soybean, and that this loss is restored by supplementation of the diet with lysine and methionine ${ }^{9-11}$ or lysine, methionine, and cystine. ${ }^{12}$ At levels of $10 \%$ dietary protein $(1.6 \%$ nitrogen levels), Iriarte $e$ al ${ }^{13 !}$ reported that cystine supplementation to overheated soybean products promoted growth of rats very much, but addition of lysine, threonine, histidine, and tryptophan either with methionine or with cystine, did not improve nutritive quality above that obtained with methionine or cystine alone. The results presented in this paper show that addition of mixture of lysine, arginine, tryptophan, and serine did improve the nutritive quality of overheated soybean flour. This may be due to the effect of additional arginine and serine, which were not used in the Iriarte's experiment, or to supplementation of lysine, threonine, histidine, 


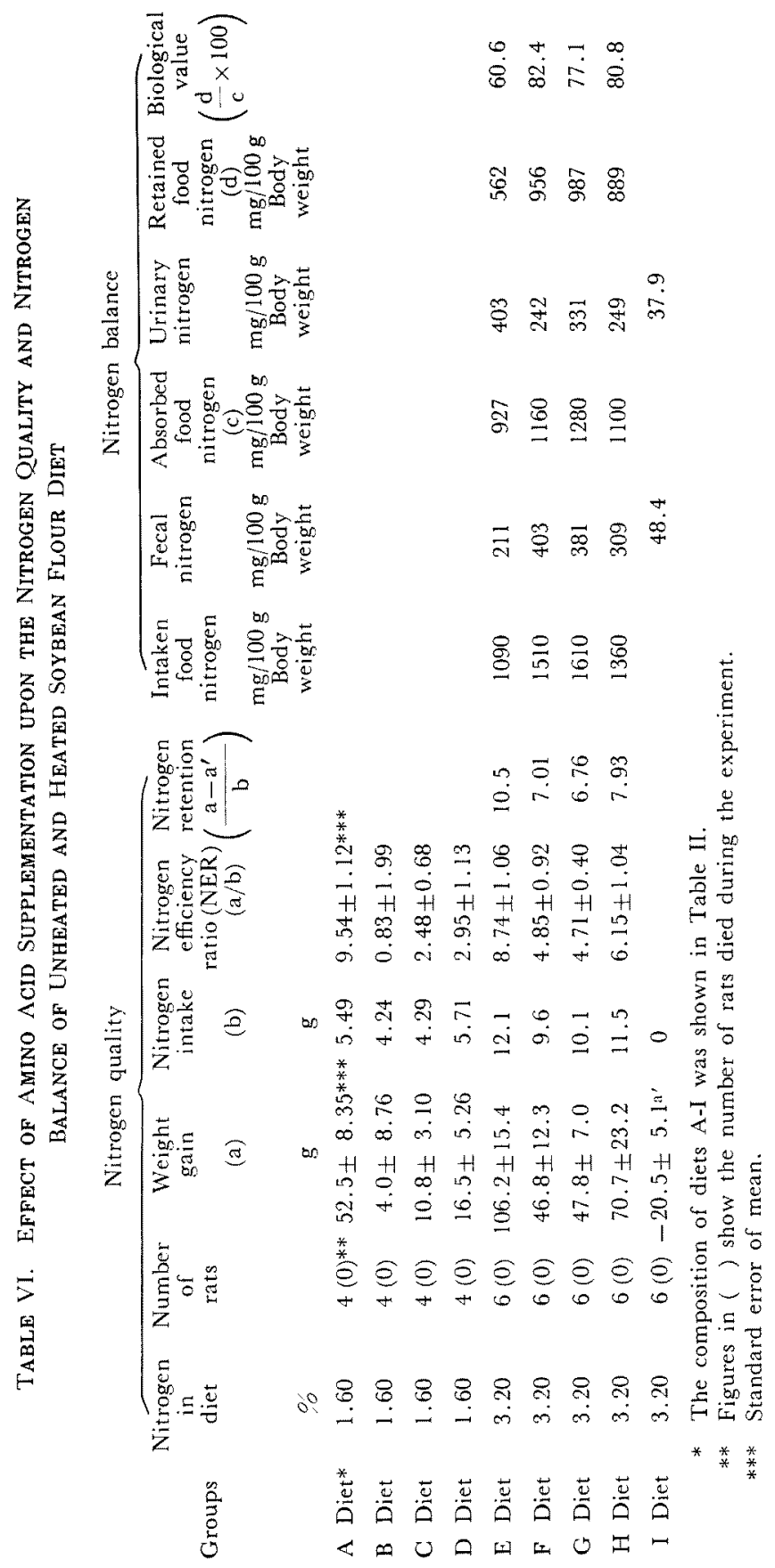


and tryptophan, individually, along with large quantity of cystine $(0.39 \%)$ used in the diets of their experiment. It is considered that the quantity of added cystine $(0.3 \%)$ was far more than that destroyed during overheating of soybean flour. Supplementation of large quantity of cystine, the principal limiting amino acid (sulphur containing amino acid) in soybean, led to over-grow of the rat owing to the restoration of the decreased nutritive value. Consequently, the supplemental effect of amino acids except cystine could not be detected in the Iriarte's work. On the other hand, in our results, the additional effect of mixture of lysine, arginine, histidine, tryptophan, and serine on NER was not found in the dietary nitrogen levels of $3.2 \circ$, and the NER showed the same ratio as that of overheated soybean flour, but conspicuous increasing of NER was found on the cystine supplemented diet. It is evident that the supplementation of lost amount of lysine, arginine, histidine, tryptophan, and serine except cystine was not necessary for rat to get further growth on the overheated soybean flour at the nitrogen levels of $3.2 \%$.

b. Nitrogen balance. The nitrogen balance was evaluated from the difference of nitrogen intake in food and that excreted in feces and urine, when the dietary nitrogen level was $3.2 \%$. The excretory nitrogen increased considerably in the feces when overheated flour was used in the diet, but when the lost amino acids were supplemented, the fecal excretion decreased gradually. On the other hand, urinary excretion did not show any tendency for correction even when the lost amino acids in the overheated flour were supplemented in the diet. The increased fecal nitrogen excretion indicates that the overheated flour decreased absorption and lowered the digestibility and that this can be corrected by supplementing the diet with the lost amino acids. Continued lower values for urinary nitrogen under further supplementation of amino acids may be due to endogenous factors. Same phenomenon was also observed in the biological value. Therefore, evaluation of nutritive value of heated samples can not be based on biological value. It can be concluded that the disagreement of tendency between biological value and rat growth i.e. NER is due to the variation in the digestive release of amino acids and absorption which is related to the quantity and quality of dietary protein.

The infuence of feeding of the heated soybean flour on rat groweth tested by incorporating the amino acid mixture similar to those released by enzymatic digestion of heated and unheated soybean flour

The results of determination of nitrogen quality and nitrogen balance are given in Table VII.

a. Nitrogen quality. Weight gain in rats of group $A^{\prime}$ fed with unheated soybean flour and of group $\mathrm{C}^{\prime}$ fed with overheated flour was lower than those in group $\mathrm{B}^{\prime}$ fed with properly heated flour. The same trend was observed in group $\mathrm{G}^{\prime}, \mathrm{H}^{\prime}$, and $\mathrm{I}^{\prime}$ where the diets were prepared from amino acid mixtures based on the amino acids released during $120 \mathrm{hr}$ enzymatic digest of unheated, properly heated, and overheated soybean flour, but the growth was lower when compared with those of $A^{\prime}$, $\mathrm{B}^{\prime}$, and $\mathrm{C}^{\prime}$ The data obtained in the case of diets $\mathrm{D}^{\prime}$. $\mathrm{E}^{\prime}$, and $\mathrm{F}^{\prime}$ (the amino acid patterns of $6 \mathrm{hr}$ enzymatic digestion period) were different and above-mentioned phenomena, which were observed in the group $\mathrm{G}^{\prime}, \mathrm{H}^{\prime}$, and $\mathrm{I}^{\prime}$, were not found.

The nutritive value of protein must obviously depend firstly on its digestibility. In evaluating protein quality of foods and feeds, the in vitro test is based on the pattern of amino acids released during enzymatic digestion of the protein. Numerous methods are available to carry out the in vitro enzymatic digestion. Akeson and Stahmann ${ }^{181}$ devised a pepsin-pancreatin digest index based on the 


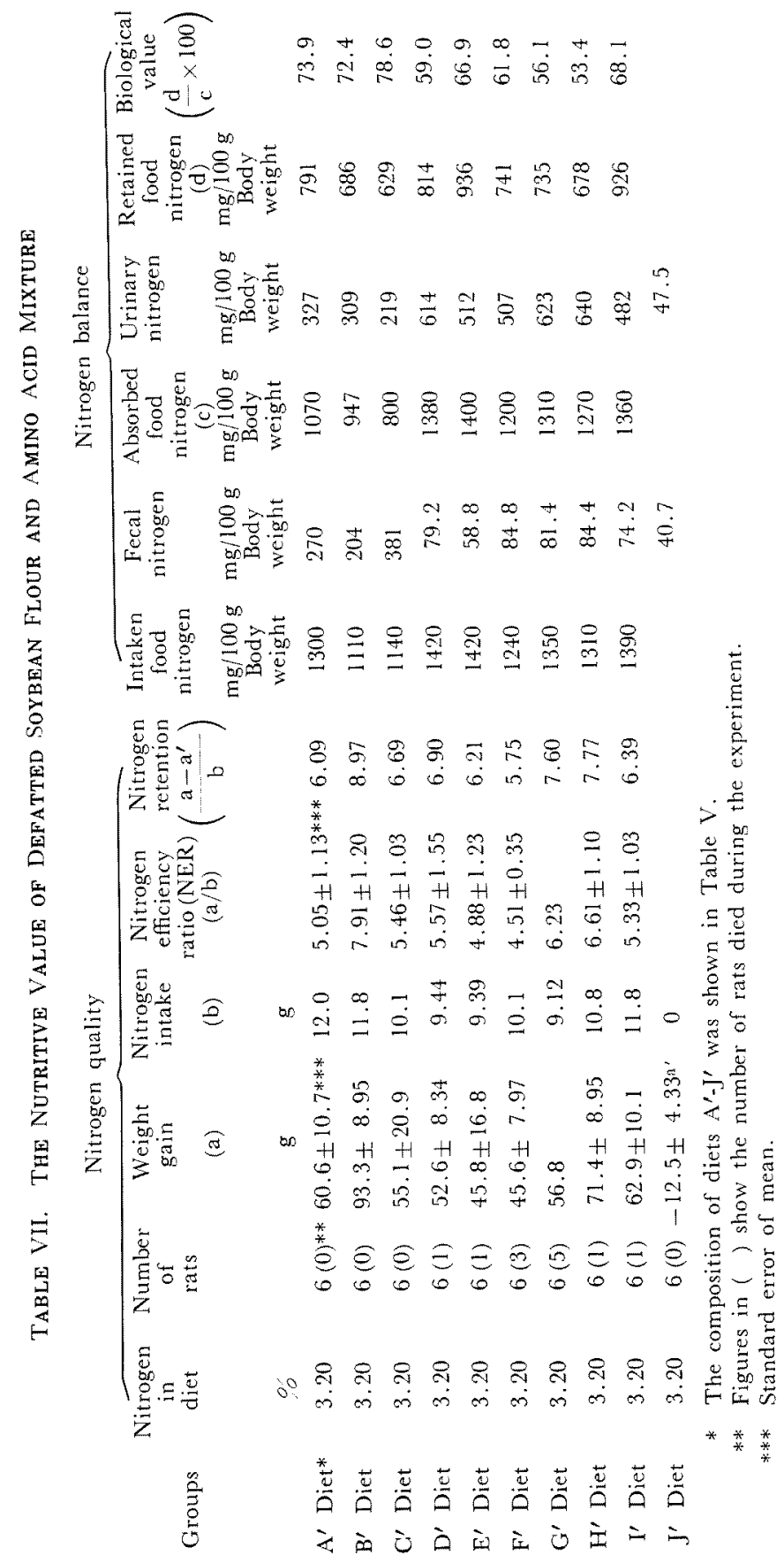


Table ViII. Selected Comparison of the Data from Table III Expressed as Percentage Changes in amino ACid Liberation by Enzymatic Digestion

The effect of heat treatment (hr)

Amino acids

Glycine
Alanine
Valine
Isoleucine
Leucine
Aspartic acid
Glutamic acid
Lysine
Arginine
Histidine
Phenylalanine
Tyrosine
Proline
Tryptophan
Methionine
Cystine
Serine
Threonine

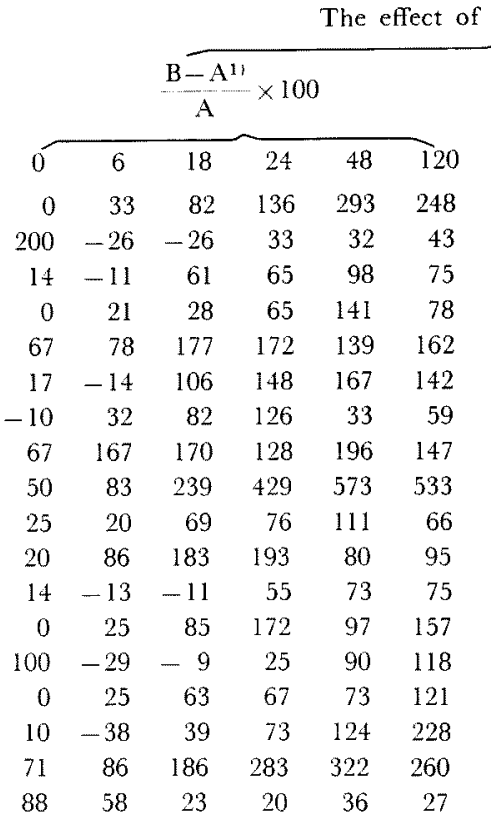

\begin{tabular}{|c|c|c|c|c|c|}
\hline & & $\frac{C-B^{21}}{B}$ & $\times 10$ & & \\
\hline 0 & 6 & 18 & 24 & 48 & 120 \\
\hline 100 & 239 & 145 & 55 & 16 & 6 \\
\hline 83 & 9 & 0 & -22 & -22 & 10 \\
\hline 63 & 153 & 76 & 61 & 31 & 5 \\
\hline 40 & 59 & 68 & 8 & -7 & -11 \\
\hline 100 & 238 & 172 & 122 & 70 & 17 \\
\hline 79 & 204 & 14 & -9 & -8 & -16 \\
\hline 33 & 97 & 69 & 53 & 59 & 43 \\
\hline 7 & 178 & 20 & 14 & -18 & -8 \\
\hline 219 & 311 & 89 & 55 & 25 & 5 \\
\hline 50 & 128 & 50 & 15 & 4 & -22 \\
\hline 175 & 195 & 68 & 47 & 30 & 3 \\
\hline 100 & 55 & 102 & 23 & 36 & -4 \\
\hline 67 & 130 & 96 & 18 & 23 & -5 \\
\hline-33 & 95 & 77 & 12 & 9 & -14 \\
\hline 50 & 150 & 108 & 50 & 42 & 2 \\
\hline-45 & 96 & 79 & 16 & 6 & -44 \\
\hline 92 & 169 & 112 & 69 & 25 & 16 \\
\hline 147 & 90 & 4 & 0 & -5 & -11 \\
\hline
\end{tabular}

1) Properly heated $\left(108^{\circ} \mathrm{C}, 1 \mathrm{hr}\right)$ defatted soybean flour (B) vs. unheated defatted soybean flour (A).

2) Overheated $\left(126^{\circ} \mathrm{C}, 4 \mathrm{hr}\right)$ defatted soybean flour $(\mathrm{C})$ vs. properly heated $\left(108^{\circ} \mathrm{C}, 1 \mathrm{hr}\right)$ defatted soybean flour (B).

amino acids released during in vitro digestion estimated by chromatographic procedure. This index showed better correlation with the biological value for rat growth than that with the essential amino acid index which gives higher values or with the chemical score where the values are lower. Some authors ${ }^{3,14,16,18,231}$ prefer enzymatic hydrolysis with pancreatin only. Melnick and Oser ${ }^{14}$ have reported that in evaluating nutritive value of products improved or impaired by heat-processing and exhibiting no change in amino acid composition or degree of digestibility, the rate of enzymatic digestion is critical. They are also of the view that for optimal utilization of food proteins, all essential amino acids must

23) E. Menden and H.D. Cremer, Nutr. Dieta., 8, 188 (1966). not only be available for absorption but also must be liberated during in vitro digestion at rates permitting mutual supplementation. In this experiment, the proportions of amino acid mixtures were based upon the released amino acid pattern. As compared properly heated flour with unheated flour, or overheated flour with properly heated flour in liberated amino acid percentage, it was observed that the extent of the release of each of various amino acids by enzymes increased by proper heating, but decreased by prolonged heat treatment of the protein, and the rate of release of the amino acid varied widely (Table VIII).

It was also observed that pattern of released amino acids differed during different stages of digestion (Table VIII). Between 6 and $18 \mathrm{hr}$ reaction period, digestibility of overheated soybean flour was higher than that of the 
properly heated flour. Moreover, the pattern of released amino acids also varied in the two treatments. There was variation in glycine, valine, arginine, histidine, phenylalanine, proline, methionine, and serine contents of the hydrolysates obtained after $6 \mathrm{hr}$ digestion whereas the $120 \mathrm{hr}$ hydrolysate differed in leucine, aspartic acid, glutamic acid, histidine, tryptophan, cystine, and serine contents. It is clear that heating causes denaturation of protein and that this has a profound influence on the biological value. The results obtained in these experiments clearly show that there is agreement between the growth of rats fed on unheated soybean flour and those fed on a diet based on the amino acid mixtures released during $120 \mathrm{hr}$ enzymatic digestion.

Deshpande et al. ${ }^{24}$ agreed that the results of in vitro studies can not be used as an index of the availability of the amino acids in animal studies because the digestive products and their absorption affect the release of amino acids in vitro. Recently, Szmelcman and Guggenheim ${ }^{251}$ have reported that in vitro assay of available amino acids serves only as a guide to the quantity of amino acids which will be released by enzymatic digestion in the intestines. In the present studies, in vitro evaluation of protein quality by pancreatic digestion has been found useful for assessing the quality of unheated, properly heated, and overheated soybean flour. The reduction in the nutritive value of overheated soybean flour may be due to the irregular release of amino acids and availability of amino acid after absorption.

b. Nitrogen balance. Metabolism trials indicate that overheated defatted soybean flour excretes more fecal nitrogen when compared with properly heated flour (Table VII). Same results were observed in group $\mathrm{D}^{\prime}, \mathrm{E}^{\prime}$, and $\mathrm{F}^{\prime}$

24) P. D. Deshpande, A. E. Harper, M. Collins and C. A. Elvehjem, Arch. Biochem. Biophys., 67, 341 (1957).

25) S. Szmelcman and K. Guggenheim, J. Sci. Food Agric., 18, 347 (1967). in which the similar amount of amino acid mixture to the pattern released by $6 \mathrm{hr}$ digestion was added to their diets. But no significant difference in fecal nitrogen was observed in the diet groups $\mathrm{G}^{\prime}, \mathrm{H}^{\prime}$, and $\mathrm{I}^{\prime}$. From these data, it would be possible to conclude that diets $D^{\prime}, E^{\prime}$, and $F^{\prime}$ showed more fecal nitrogen excretion due to the irregular amino acid pattern.

Amino acid mixture diets also show lower fecal nitrogen losses when compared with heated and unheated soybean flour diets. It is assumed that the nitrogen absorption is greater when the amino acid mixture diets are used. On the contrary, urinary nitrogen losses of unheated or heated soybean flour were small when compared with amino acid diets. From these data, it may be surmised that the utilization of the amino acid mixture diets may be less than that of the defatted soybean flour because of the increased excretion of nitrogen in urine.

Biological value of unheated, properly heat$\mathrm{ed}$, and overheated defatted soybean flour diets did not agree with rat growth: the superiolity of properly heated soybean flour diet $\left(\mathrm{B}^{\prime}\right)$ in rat growth was not observed in biological value. This finding is in agreement with the results of amino acid supplemental test presented in Table VI. Mitchell and Hamilton $^{26)}$ have reported that the biological values of protein increased with decreasing protein content of the diet. The biological value also varies with increase in the level of soybean oil meal in the feed. ${ }^{27)}$ Further, Forbes et al ${ }^{281}$ have reported that the biological value decreased linearly for three different proteins as the protein concentration increased, and the rate of change in calculated biological value also varied with increasing feed levels

26) H.H. Mitchell and T.S. Hamilton, "The Biochemistry of the Amino Acids". Little and Ives, New York, 1929.

27) R. M. Forbes and M. Yohe, J. Nutr., 55, 499 (1955).

28) R. M. Forbes, M. Yohe and L. Vaughan, Federation Proc., 15, 551 (1956). 
of each protein. The similar observation was made when the amino acid mixture diets were used. The biological value of amino acid diets was lower than that of defatted soybean flour, and this finding coincides with that reported by Murlin and his associates. ${ }^{291}$

According to the data presented in this paper, inaccuracy of biological values of defatted soybean flour may have been caused

29) J. R. Murlin, L. E. Edwards, E. E. Hawley and L. C. Clark, J. Nutr., 31, 555 (1946). by a change in the property of protein (i.e. amino acid destruction or decrease in amino acids released by enzymatic digestion), and these problems raise the question of the validity with respect to nutritional evaluation of biological value for heat damaged defatted soybean flour samples.

Acknowledgement. The authors wish to express their sincere thanks to Prof. Yosito Sakurai of the Japan Women's University for his helpful suggestions and continued interest throughout these investigations. 